DOSSIÊ

\title{
A ruptura na politica externa brasileira e suas dimensões doméstica e geopolítica: subordinação internacional, fragmentação regional e resposta à pandemia
}

The rupture in Brazilian foreign policy and

its domestic and geopolitical dimensions:

international subordination, regional

fragmentation and response to the pandemic

\section{Tỉago Nerly*}

DOI: https://doi.org/10.4322/principios.2675-6609.2020.160.004

Embaixada dos EUA no Brasil / Divulgação

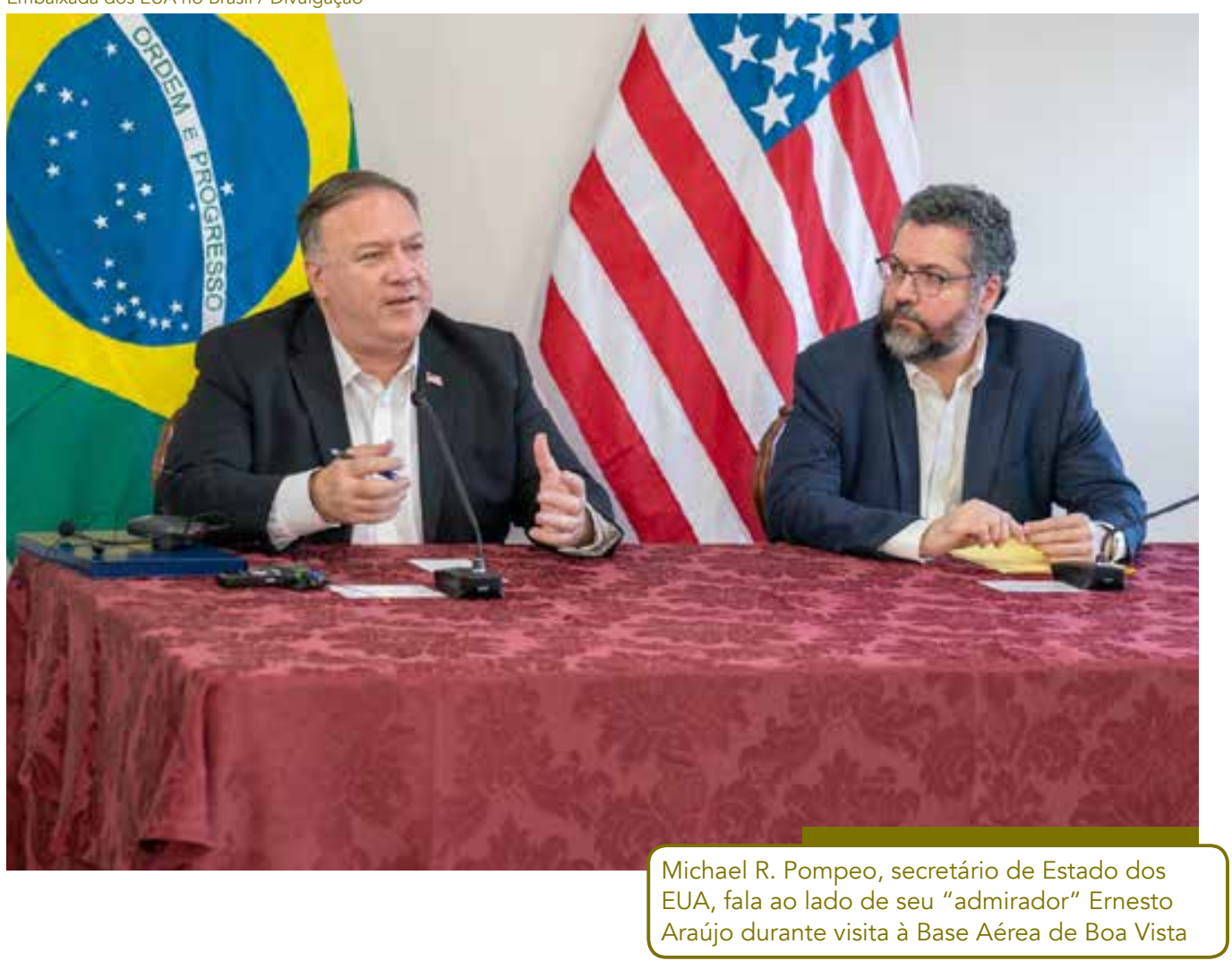

$\underline{88}$ 


\section{RESUMO}

A compreensão da política externa requer a análise de suas dimensões sistêmica e doméstica. A crescente rivalidade entre China e Estados Unidos e a crise do capitalismo pós-2008 impactaram os governos progressistas da América Latina e contribuíram para a ascensão de coalizões de extrema-direita na região. Historicamente, a política externa brasileira foi vista como uma política de Estado imune a interferências externas. Todavia, os processos de redemocratização e globalização contribuíram para a pluralização e politização da política exterior. Entre 1994 e 20I4, a política externa foi uma arena de disputa entre coalizões políticas com distintas visões sobre a inserção do país nos planos internacional e regional. A eleição de 2018 marcou uma ruptura na trajetória diplomática brasileira. $\mathrm{O}$ atual presidente tem isolado o Brasil internacionalmente ao subordinar os interesses do país aos Estados Unidos. No âmbito regional, a política externa tem violado os princípios constitucionais que regem as relações internacionais do país, ameaçando as relações pacíficas com os vizinhos e deixando de desempenhar um papel de estabilização na região. A pandemia aumentou a rivalidade sino-americana e trouxe impactos negativos para a democracia, com o aumento das desigualdades sociais, especialmente na América Latina. A resposta do governo brasileiro tem sido desastrosa. Internamente, observa-se a falta de coordenação federativa e o conflito entre os poderes. No plano internacional, a política externa brasileira tem sido responsável pela desconstrução da histórica atuação do Brasil na área de saúde, tanto no plano multilateral quanto no âmbito regional.

Palavras-chave: Política externa brasileira. Geopolítica. Coalizões domésticas. Integração regional. Covid-I9.

\section{ABSTRACT}

Understanding foreign policy requires an analysis of its systemic and domestic dimensions. The growing rivalry between China and the United States, and the post-2008 crisis of capitalism, impacted Latin American progressive governments and contributed to the rise of far-right coalitions in the region. Historically, Brazilian foreign policy has been seen as a state policy immune to external interference. However, the processes of redemocratization and globalization contributed to the pluralization and politicization of foreign policy. Between I994 and 20I4, foreign policy was an arena of dispute between political coalitions with different views on the insertion of the country at the international and regional levels. The 2018 election marked a break in the Brazilian diplomatic trajectory. The current president has isolated Brazil internationally by subordinating the country's interests to the United States. At the regional level, foreign policy has violated the constitutional principles that govern the country's international relations, threatening peaceful 


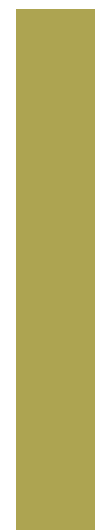

relations with neighbors and failing to play a stabilizing role in the region. The pandemic has increased Chinese-American rivalry and has had negative impacts on democracy, with increasing social inequalities, especially in Latin America. The Brazilian government's response has been disastrous. Internally, there is a lack of federative coordination and the conflict between powers. At the international level, Brazilian foreign policy has been responsible for deconstructing Brazil's historic performance in the health area, both at the multilateral and regional levels.

Keywords: Brazilian foreign policy. Geopolitics. Domestic coalitions. Regional integration. Covid-I9.

\section{INTRODUCÃA}

A compreensão dos processos políticos contemporâneos, inclusive da política externa de qualquer país, requer a análise dos níveis sistêmico e doméstico. No plano sistêmico ou estrutural, caracterizado por assimetrias e desigualdades, é preciso observar as contradições do sistema capitalista e seu impacto nas rivalidades e nas relações de poder entre os Estados. No âmbito interno, faz-se necessário analisar as coalizões políticas e as tensões entre os diferentes atores estatais e não estatais.

Durante anos, a política externa brasileira foi percebida como uma política de Estado, imune à interferência de órgãos governamentais, empresas, sindicatos, partidos políticos e outros atores da sociedade civil. O fim da Guerra Fria e os processos de redemocratização e globalização contribuíram para a politização da política externa, levando à pluralização de seus atores, à introdução de novos temas e à complexificação de seu processo decisório. Apesar de envolver questões permanentes, a política externa também é uma política pública que se insere em uma arena de contingência, conflito e transitoriedade.

O presente artigo está dividido em quatro seções, além desta introdução e da conclusão. A primeira seção analisa o impacto da dimensão estrutural ou sistêmica no Brasil e na América Latina. O fim do boom de commodities coincidiu com o recrudescimento da competição entre a potência hegemônica, os Estados Unidos, e a potência ascendente, a China, com reflexos na região. Os conflitos geopolíticos se somaram aos efeitos da crise de 2008 , que acelerou as tensões entre capitalismo e democracia e levou ao advento de uma onda conservadora mundial, na qual se insere o atual governo brasileiro.

A segunda seção analisa as relações entre as coalizões políticas domésticas e a política externa brasileira. Entre 1994 e 20I4, o sistema político foi estruturado em torno da polarização entre o Partido da Social-Democracia Brasileira (PSDB) e o Partido dos Trabalhadores (PT). O PSDB liderou uma coalizão de centro-direita que tentou conjugar a estabilidade e as reformas pró-mercado, no âmbito doméstico, com uma política externa de "prestígio", de adesão acrítica à globalização financeira e aos 
regimes internacionais. Por sua vez, o PT liderou uma coalizão de centro-esquerda que combinou uma política econômica neodesenvolvimentista com uma política externa autônoma, que institucionalizou coalizões Sul-Sul e priorizou a integração da América do Sul. Apesar de suas diferentes visões sobre a inserção internacional e regional do Brasil, ambos os partidos respeitaram os princípios constitucionais que orientam as relações internacionais do país e mantiveram políticas amistosas com os vizinhos. A eleição presidencial de 2018 foi disruptiva e levou ao poder o candidato de extrema-direita Jair Bolsonaro. Além de ameaçar as instituições democráticas, a coalizão liderada por Bolsonaro provocou uma ruptura na trajetória da política externa brasileira, sobretudo ao subordinar o Brasil ao governo Donald Trump e aos interesses dos Estados Unidos.

$\mathrm{Na}$ terceira seção, analisa-se a política externa brasileira para a América do Sul. Apesar de conceberem a integração regional nos marcos do chamado regionalismo aberto, os governos tucanos priorizaram o Mercosul e foram responsáveis pela primeira reunião de presidentes da América do Sul. Os governos petistas, sobretudo o de Lula, priorizaram a integração regional em um grau inédito na história diplomática do país. O Brasil reconheceu as assimetrias do Mercosul e introduziu novas dimensões no bloco, contribuindo decisivamente também para a criação da União de Nações Sul-Americanas (Unasul) e da Comunidade de Estados Latino-Americanos e Caribenhos (Celac). No entanto, desde o golpe parlamentar que derrubou a presidenta Dilma, em 20I6, o Brasil vem hostilizando alguns países da região e desconstruindo uma política externa que era admirada e contribuía para a estabilidade regional. Ao subornar o país à potência hemisférica, o Brasil se isolou nos planos global e regional.

Por fim, a quarta seção destaca os impactos da covid-I9 na ordem internacional e analisa brevemente a resposta do governo Bolsonaro à pandemia. O novo coronavírus acelerou a rivalidade geopolítica entre a China e os Estados Unidos, impactou negativamente os regimes democráticos em alguns países e aumentou as desigualdades sociais e a pobreza, especialmente na América Latina, região mais afetada do mundo até o momento. A resposta do governo brasileiro à crise sanitária tem sido desastrosa. No âmbito doméstico, houve falta coordenação entre os entes federados e conflito entre os poderes. Por sua vez, o alinhamento da política externa brasileira aos Estados Unidos tem levado ao crescente isolamento do Brasil nos planos internacional e regional.

\section{CONFLITOS GEOPOLIITICOS E CRISE DA DEMOCRACIA NA AMÉRICA LATINA E NO BRASIL}

Nos últimos 30 anos, transformações estruturais do sistema capitalista e da ordem política mundial provocaram impactos variados nas perspectivas de inserção internacional dos países latino-americanos. Com a queda do Muro de Berlim (1989) e o colapso da União Soviética (I99I), o mundo passou por um momento unipolar e por uma euforia liberal, de crença absoluta na racionalidade das forças de mercado. 
Na primeira década do século XXI, entretanto, a ascensão da China, a recuperação da Rússia e o revisionismo de alguns países em desenvolvimento, como o Brasil, a Índia e a África do Sul, apontaram para a constituição de uma ordem multipolar. Ademais, a crise de 2008 abalou os alicerces do neoliberalismo, conquanto fosse incapaz de impedir o crescente divórcio entre capitalismo e democracia.

A ideia de uma economia pura, desprovida de toda e qualquer instituição jurídica ou política, não corresponde à realidade. Ao contrário do que as teorias neoclássicas e a ideologia neoliberal fazem acreditar, o capitalismo não é um estado natural, mas uma ordem social, concretizada sob formas que variam conforme o lugar e ao longo da história, podendo, em princípio, ser negociada e estando permanentemente ameaçada de ruptura (BOYER, 2009; STREECK, 2018).

Entre 1945 e 1973, o capitalismo passou por uma situação defensiva em todo o mundo. A ordem de Bretton Woods, baseada no controle de capitais, no sistema de taxas de câmbio fixas e no padrão dólar-ouro, foi responsável pela chamada "era dourada do capitalismo", marcada por altas taxas de crescimento e inclusão social, sobretudo nos países centrais. A marca registrada dessa ordem econômica foi a subordinação da economia à política. Assim, as três décadas do pós-guerra foram uma época em que a economia de mercado capitalista deixou de se apresentar como um fenômeno natural, tal qual no liberalismo clássico, e passou a se mostrar como construção política.

A partir de 1973, todavia, ressurgiram os teóricos do livre mercado, como Friedrich Hayek e Milton Friedman, atribuindo a recessão econômica e suas consequências nefastas ao "governo inchado", ao Estado. A prioridade central do consenso keynesiano - a conjunção entre crescimento econômico e pleno emprego - cedeu lugar ao controle da inflação e à resolução dos conflitos distributivos e de poder a favor das classes proprietárias (JUDT, 2008; SERRANO, 2004). O processo de financeirização levou à dissolução progressiva do casamento arranjado entre capitalismo e democracia que caracterizou a ordem do pós-guerra. Com isso, a base de legitimação do capitalismo transferiu-se da política para o mercado. Assim, o sociólogo Wolfgang Streeck (STREECK, 20I8, p. 55) tem razão ao destacar o progressivo processo de "desdemocratização do capitalismo por meio de deseconomização da democracia", fenômeno que tem avançado em todo o mundo desde a crise de 2008.

A crise de 2008 é a maior crise do capitalismo desde 1929. No entanto, as respostas dos países centrais, sobretudo do eixo anglo-saxão, foram bem diferentes. No rastro da crise de I929, a eleição de Franklin Delano Roosevelt e o New Deal significaram que a crise deveria ser resolvida por meios políticos. Após a crise de 2008, o equilíbrio de poder foi diverso: a autoridade política se enfraqueceu diante das forças de mercado (VAROUFAKIS, 20I6).

A grande recessão de 2008 coincidiu com o recrudescimento da rivalidade entre os Estados Unidos e a China. Entre 20I5 e 20I6, a "recuperação" da economia estadunidense foi de aproximadamente I,2\% ao ano. No mesmo período, a economia 


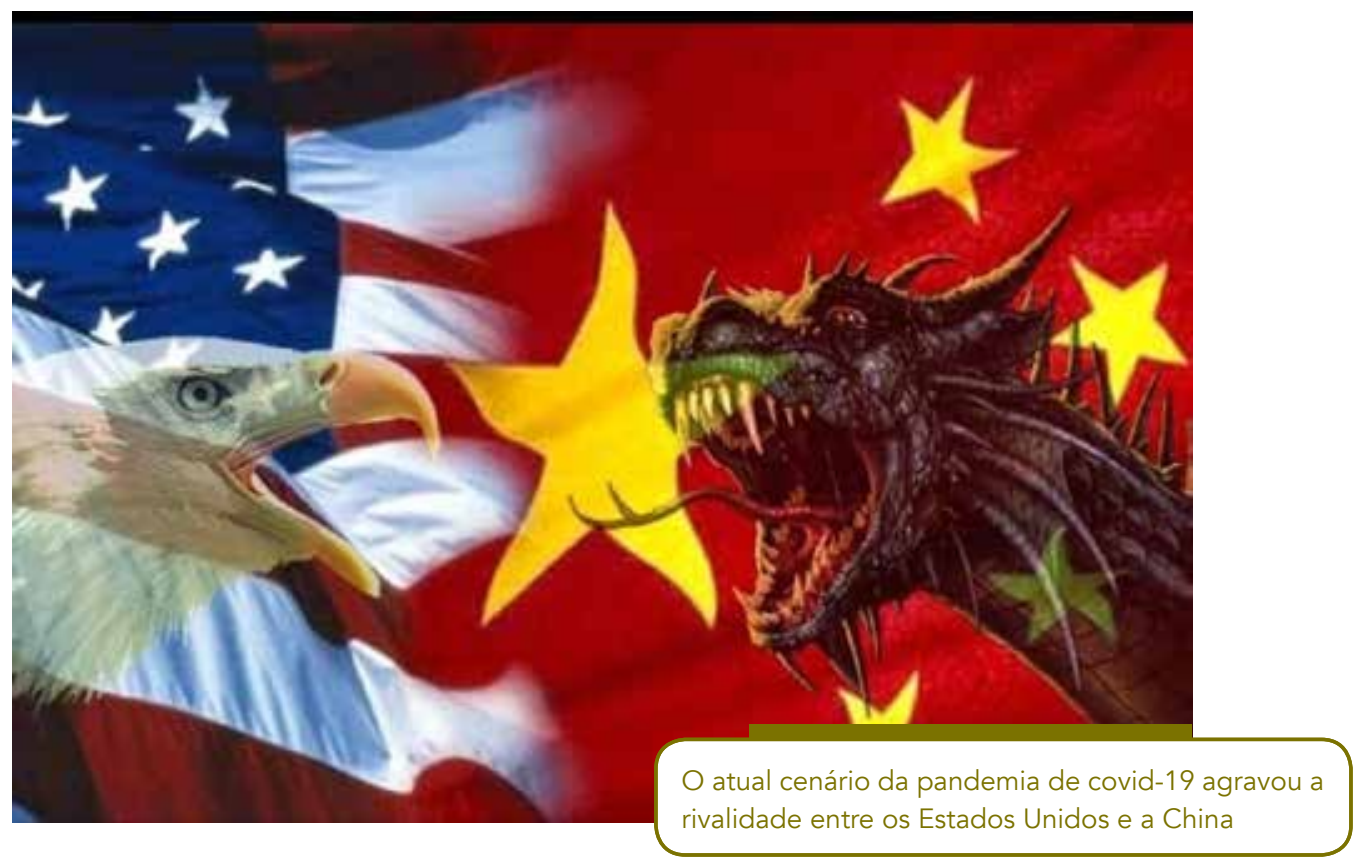

chinesa, que havia crescido em média I0\% ao ano antes da crise, alcançou um crescimento de $6 \%$ a $7 \%$ anuais. Isso representa $40 \%$ de todo o crescimento global desde a crise de 2008 (ALLISON, 20I8).

Desde o fim da Guerra fria, o panorama estratégico global passou por algumas mutações. Nos anos I990, o mundo viveu seu momento unipolar, isto é, a hegemonia da superpotência remanescente. Já na primeira década do século XXI, houve uma redistribuição mundial do poder, do Ocidente para o Oriente e do Norte para o Sul (AMORIM, 20I6). A ascensão de nações em desenvolvimento apontou para uma nascente multipolaridade. Nesse período, surgiram arranjos importantes como o Brics (Brasil, Rússia, Índia, China e África do Sul) e o Fórum Ibas (Índia, Brasil e África do Sul), no plano global, e a Unasul e a Celac, no plano regional. A formação dessas coalizões e desses blocos contou com o apoio decisivo do governo Lula e da política externa "altiva e ativa" do chanceler Celso Amorim.

Atualmente, muitos analistas defendem a noção de que o mundo vive uma nova ordem que pode ser chamada de "bipolaridade assimétrica", envolvendo os Estados Unidos e a China. Em 20I4, relatório do Fundo Monetário Internacional (FMI) sobre a economia global atestou que, pelo critério da paridade do poder de compra (PPC), a economia chinesa havia superado a estadunidense. Como a maioria dos analistas das relações internacionais acredita que o poder militar deriva do poder econômico, a ascensão do gigante asiático seria precursora da sua predominância e hegemonia militares (ALLISON, 20I8; STUENKEL, 20I8).

A crescente rivalidade entre os Estados Unidos e a China levou o analista Graham Allison a se perguntar se ambos os países poderiam escapar à chamada "armadilha de Tucídides". Segundo Allison (2018), desde o conflito entre Atenas e Esparta, toda vez que uma potência ascendente ameaça deslocar a potência dominante, 
a eclosão de um conflito violento torna-se a regra, e não a exceção. Nos últimos 500 anos, nas I6 vezes em que tal cenário emergiu, I2 resultaram em guerra.

$\mathrm{O}$ atual cenário da pandemia da covid-I9 agravou a rivalidade entre os Estados Unidos e a China. O governo Donald Trump e outros governos conservadores responsabilizam a China pela eclosão da pandemia e a Organização Mundial da Saúde (OMS) pela demora na resposta. Essa postura é seguida pelo governo Bolsonaro e pelo chanceler Ernesto Araújo, para quem o multilateralismo é um instrumento do globalismo e do "marxismo cultural" (ALBUQUERQUE, 2020).

A rivalidade entre os Estados Unidos e a China teve reflexos diretos na América Latina e no Brasil. Nesse contexto de transição estrutural do sistema internacional, a potência hegemônica vem trabalhando para enfraquecer a influência chinesa e restaurar sua hegemonia no Hemisfério Ocidental, sua histórica área de dominação.

A ascensão dos governos progressistas na América Latina coincidiu com o boom de commodities provocado pela demanda chinesa e pelas altas taxas de crescimento do gigante asiático. Entre 2003 e 2008, o PIB da região cresceu em média 5\% ao ano. Nesse período, a China ampliou significativamente sua presença na região. Entre 2007 e 2017, o comércio entre a China e a América Latina aumentou 22 vezes, chegando a US\$ 258 bilhões ao final desse decênio. Atualmente, quase todos os países latino-americanos têm a China como principal parceiro comercial (o Brasil, desde 2009). Além disso, a China tem realizado maciços investimentos em infraestrutura em todo o continente, com clara ênfase em conectividade - aeroportos, estradas, portos, telecomunicações, tecnologia informacional etc. —, no âmbito do guarda-chuva da iniciativa "Um Cinturão, Uma Rota” - "One Belt, One Road” (Obor) —, conhecida popularmente como "Nova Rota da Seda" (BELÉM LOPES, 2020; CEPIK, 20I9; COGGIOLA, 20I9; VAROUFAKIS, 20I6).

No entanto, a crescente presença chinesa trouxe não apenas oportunidades, mas também problemas. De um lado, o crescimento econômico chinês, ao melhorar os termos de troca dos produtos exportados pela região, permitiu aos governos progressistas adotar políticas sociais inclusivas, que retiraram milhões de pessoas da pobreza, e políticas externas mais autônomas. Como exemplos desse momento de maior autonomia, podem-se destacar os papéis do Brics e do Fórum China-Celac. De outro lado, a presença chinesa aprofundou a desindustrialização e a reprimarização das economias latino-americanas, reproduzindo a dinâmica centro-periferia que historicamente tem marcado a inserção internacional da América Latina na economia mundial.

A mudança nos padrões comerciais da América Latina afetou a orientação de uma região situada na área de influência da potência hegemônica. Os governos Lula e os demais governos progressistas da região tinham navegado em uma zona de conforto. Em 2012, o crescimento da China caiu pela metade em relação a 2007, arrastando para baixo a América do Sul (SINGER, 20I8; VAROUFAKIS, 20I6). O fim da "década de prosperidade" coincidiu com o recrudescimento da rivalidade sino-americana e 
com a intensificação dos conflitos distributivos nos países latino-americanos, levando ao poder governos conservadores e de extrema-direita.

Desde o governo Obama, o objetivo estratégico dos Estados Unidos era reverter a chamada "maré rosa", desestabilizando os governos progressistas na América Latina, sobretudo na América do Sul. A ofensiva estadunidense incluía desde o reforço das bases militares estabelecidas na Colômbia e em outros países da América Central e do Caribe (são 76 bases em toda a América Latina) até a reativação da IV Frota Naval. Ademais, os Estados Unidos tiveram participação decisiva na derrubada dos governos de Honduras, em 2009, do Paraguai, em 20I2, e do Brasil, em 2016 (AMORIM, 20I9; COGGIOLA, 20I9).

O golpe no Brasil, que encerrou o ciclo de governos liderados pelo PT, não foi um processo exclusivamente de "conteúdo nacional". A política externa autônoma e a descoberta do petróleo do pré-sal, cujo marco regulatório foi aprovado no final do governo Lula (e, aliás, revogado por Temer logo após sua posse), além de outras iniciativas (por exemplo, o programa de submarinos nucleares), incomodaram o imperialismo e são fundamentais para entender o movimento golpista. O governo Obama espionou a Petrobrás e a própria presidenta Dilma. Há indícios de que o Departamento de Justiça estadunidense, que foi responsável por ministrar cursos sobre investigação de corrupção a juízes e procuradores da Lava Jato, teria repassado informações para essa operação. Com efeito, os estrategistas estadunidenses viam com preocupação que um país das dimensões do Brasil adotasse uma política externa autônoma, sobretudo em relação a Washington (AMORIM, 20I9; BOITO JR., 20I8). Ao analisar o golpe, Wanderley Guilherme dos Santos conclui: "com atraso de quase uma década, o Brasil se aproxima do padrão reacionário do mundo moderno, antecedido por recente inovação política do capitalismo: um golpe de Estado com origem e sustentação parlamentares" (SANTOS, 20I7, p. I3I-I32).

No governo Trump, o imperialismo estadunidense intensificou suas ações na América Latina. Trump aumentou o cerco econômico a Cuba e à Venezuela, ameaçando invadir o país sul-americano. Além disso, o presidente estadunidense tem trabalhado para enfraquecer a influência chinesa e russa na região. Segundo Cepik (2019), analistas ligados ao Pentágono começaram a considerar a presença chinesa na América Latina como uma ameaça para a segurança dos Estados Unidos antes mesmo da Casa Branca. No final de 2017 , tal avaliação se tornou política oficial em Washington.

Segundo a atual "Estratégia de segurança nacional" (NSS) dos Estados Unidos, a China busca colocar a região em sua órbita por meio de investimentos e empréstimos dirigidos liderados pelo Estado. O governo Trump vem tentando impor a ideia de que a presença chinesa seria uma ameaça comum a todos os países. Segundo o corolário Trump sobre a China, o gigante asiático quer ou pode deslocar os Estados Unidos para assumir a condição de hegemon regional. No entanto, tal visão não se sustenta na realidade. Os Estados Unidos seguem como principal parceiro comercial 
da maioria dos países, além de possuir inúmeras bases militares na região. Ademais, Cepik (20I9) tem razão quando afirma que a política externa estadunidense deve ser analisada sempre no contexto da grande estratégia global daquele país, vis-à-vis à inserção semiperiférica, subordinada e desunida da América Latina.

Nos últimos 70 anos, a estratégia dos Estados Unidos para a América Latina mudou de nome algumas vezes. Durante a Guerra Fria, ficou conhecida como "combate à subversão comunista". Em seguida, veio a "guerra às drogas" e a "guerra ao terrorismo". Mais recentemente, os estrategistas estadunidenses inovaram com a "guerra contra a corrupção". Apesar das diferentes nomenclaturas, permaneceu invariável a determinação de Washington de impedir o surgimento de um polo de poder autônomo na região. Daí a aversão da potência hegemônica a projetos como o Mercosul e, sobretudo, a Unasul. Assim, o aumento da pressão competitiva no sistema internacional e a erosão continuada das relações entre capitalismo e democracia tiveram impacto na América Latina e no Brasil, provocando alterações na correlação de forças domésticas e a ascensão de governos de direita e extrema-direita.

\section{POLÍTICA EXTERNA BRASILEIRA: DAS DIFERENÇAS ENTRE PSDB E PT À RUPTURA APÓS 2018}

A partir dos anos I980, os processos de redemocratização e de globalização econômica levaram à perda gradativa do papel do Ministério das Relações Exteriores no processo decisório da política externa brasileira. Desde então, a política externa passou a incorporar novos atores (partidos políticos, empresários, sindicatos, movimentos sociais, organizações não governamentais etc.) e novos temas para além das questões relativas à defesa e à segurança. Apesar das diferentes visões sobre a inserção internacional e regional do Brasil, os governos do PSDB e do PT adotaram estratégias que mesclavam seus valores com certa dose de pragmatismo. A atual política externa, entretanto, rompe com a trajetória histórica da diplomacia brasileira, adotando um alinhamento automático à potência hegemônica e hostilizando alguns vizinhos, o que compromete a estabilidade e a paz na América do Sul.

A democratização da política externa representa a adequação dessa política, que é uma política pública, ao regime político do país. Trata-se de uma política pública sui generis, pois é uma política de Estado que envolve agendas permanentes (defesa, segurança, território etc.), mas é também uma política governamental que está inserida na arena de confrontos políticos. Além disso, a democratização provocou a politização da política externa, entendida como a intensificação do debate de ideias, interesses e valores em torno de escolhas políticas, que envolvem disputas entre diferentes burocracias e indivíduos (BELÉM LOPES, 2020; MILANI; PINHEIRO, 20I7).

Desde os anos I990, o processo decisório da política externa tem se tornado mais complexo. O declínio do Itamaraty como formulador central e o crescente protagonismo de outras agências burocráticas e dos partidos políticos têm deslocado o centro gravitacional do processo decisório, tornando a política externa simultaneamente 


\section{Nos últimos 70 anos, a estratégia dos Estados Unidos para a América} Latina mudou de nome algumas vezes. Durante a Guerra Fria, ficou conhecida como "combate à subversão comunista”. Em seguida, veio a "guerra às drogas" e a "guerra ao terrorismo". Mais recentemente, os estrategistas estadunidenses inovaram com a "guerra contra a corrupção"

mais sensível ao debate político e social e menos coerente e previsível ao longo do tempo (BELÉM LOPES, 2020). Apesar da recente pluralização da política externa, é preciso não superestimar o peso da participação dos novos atores (governos subnacionais, ministérios, entidades empresariais, sindicatos, organizações não governamentais, movimentos sociais etc.), que têm a sua própria agenda de política internacional e vêm influenciando cada vez mais a política externa. $O$ Itamaraty continua sendo o principal responsável pela orientação da política externa brasileira. Ademais, o fato de possuir interações com diversos atores estatais e não estatais não desfez totalmente o seu histórico e relativo insulamento burocrático.

Durante duas décadas (1994-2014), a política externa foi um dos principais campos de batalha entre PSDB e PT. Nas seis eleições presidenciais que disputaram, ambos lideraram coalizões políticas contrapostas com distintas visões sobre a inserção internacional do país. Segundo Spektor (2019), enquanto tucanos concebiam a política externa como instrumento de adaptação à globalização, buscando "credenciais de boa conduta internacional" por meio da adesão a diferentes regimes (comercial, de direitos humanos, sobre meio ambiente, de não proliferação nuclear), petistas imaginaram a diplomacia como instrumento de resistência àquilo que enxergavam como os efeitos mais perversos da globalização. Apesar de suas diferenças, PSDB e PT contribuíram para consolidar o mais longo período democrático da história do Brasil.

Nos últimos 30 anos, o poder político no Brasil foi compartilhado pela centro-direita, nos governos Fernando Henrique e Michel Temer, e pela centro-esquerda, liderada por Lula e Dilma. De acordo com Singer (2018), ao longo dos mandatos de Lula se estruturam duas coalizões contrapostas, a "rentista" e a "produtivista". O programa rentista, que tinha no PSDB seu canal privilegiado, consistia em implementar o receituário neoliberal e suas prescrições de política econômica afinadas com os câ- 
nones da teoria ortodoxa. Para a coalizão produtivista, liderada pelo PT, a meta seria impulsionar o crescimento por meio de uma intervenção do Estado que fortalecesse determinados setores econômicos ("campeões nacionais") e permitisse acelerar a distribuição de renda. Enquanto a primeira reunia o capital financeiro e a classe média tradicional, a segunda era formada por setores do chamado capital industrial/produtivo, pela fração organizada da classe trabalhadora e pelos setores desorganizados que aderiram ao "lulismo". . Por sua vez, o PMDB (MDB desde 20I7) era ligado ao agronegócio e oscilava entre as duas coalizões.

Os governos do PSDB adotaram uma política de adaptação passiva à globalização e ao status quo da ordem mundial. Ao contrário de uma estratégia autonomista, que pressupõe algum grau de revisionismo, o ativismo multilateral do governo Fernando Henrique pode ser classificado como uma típica política exterior de "prestígio". Tal estratégia objetivou incrementar a presença multilateral do país como instrumento de soft power, buscando assim compensar a ausência de hard power (PINHEIRO; LIMA, 20I8a). Assim, a política externa do PSDB procurou conciliar a estabilização monetária no plano doméstico com a adesão acrítica a regimes multilaterais, tal como o discriminatório Tratado de Não Proliferação de Armas Nucleares (TNP).

A política externa dos governos do PT caracterizou-se por um revisionismo moderado. O governo Lula adotou uma política externa autônoma e retomou elementos da Política Externa Independente (I96I-1964) e do Pragmatismo Responsável (I974-1979), a exemplo de relações mais assertivas com os países em desenvolvimento. A política externa de Lula procurou combinar a ênfase no Sul geopolítico com o aprofundamento da integração regional, especialmente na América do Sul.

A política externa de Lula e Celso Amorim contribuiu decisivamente para a institucionalização de coalizões internacionais importantes como o G-2o na Organização Mundial do Comércio (OMC), o Fórum Ibas e o Brics. A maior projeção internacional do Estado brasileiro ocorreu por meio do questionamento de algumas regras das organizações multilaterais, buscando participar da reformulação delas e do próprio ordenamento internacional, sem intencionar subvertê-lo. Em outras palavras, o Brasil nunca confrontou diretamente Washington nem pretendeu romper com a ordem ocidental. Na realidade, o país atuou como um reformador cauteloso, disposto a assumir maior parcela de responsabilidade na gestão das instituições multilaterais e na condução da ordem internacional (BOITO JR., 20I8; MILANI, 20I8; SPEKTOR, 20I9).

Em 20II, Dilma assumiu em plena recessão global, que lhe concedia menor margem de manobra para uma política externa assertiva. Alguns analistas afirmam que houve uma mudança de forma e estilo na condução da diplomacia, embora jamais admitida no discurso oficial. Conquanto a visão de mundo tenha seguido for-

1 Para Singer $(2012 ;$ 2018), o lulismo operou uma rearticulação ideológica, retirando a centralidade do conflito entre direita e esquerda e recuperando a gramática varguista que opunha pobres a ricos. Com o suporte dos setores desorganizados dos trabalhadores, o lulismo arbitraria os conflitos entre as duas coalizões de acordo com a correlação de forças, ora dando ganho de causa a uma, ora à coalizão concorrente. 
malmente em vigor, houve uma diminuição da proatividade do Brasil no cenário internacional, em um momento em que a diplomacia presidencial era crucial para manter o status quo. A política externa de Dilma enfatizou a institucionalização do Brics (a exemplo da criação do "Arranjo Contingente de Reservas e do Novo Banco de Desenvolvimento), mas conferiu pouca atenção à integração regional (MILANI, 20I8; PINHEIRO; LIMA, 20I8a).

A política externa dos governos do PT foi vista com suspeita por círculos importantes do Ocidente, sobretudo pelos Estados Unidos. A potência hegemônica percebeu como ameaças a opção estratégica pelo Sul, a crescente presença da China e a tentativa de constituição de um polo regional com a Unasul. Internamente a política externa era alvo de críticas pelos partidos de oposição e pelos grandes meios de comunicação, que a acusavam de ser ideológica e partidária. O embaixador Rubens Ricupero (RICUPERO, 20I7) chegou a afirmar que os governos do PT encerraram o longo consenso multipartidário que havia prevalecido na diplomacia brasileira desde a fundação da Nova República.

No entanto, como observam Milani e Pinheiro (20I7, p. 290), ao identificar o tempo presente como politizado em contraste com o passado, corre-se o risco de despolitizar eras passadas da política externa. A suposta neutralidade axiológica da política externa é falsa e não se sustenta na realidade. Nesse sentido, Marco Aurélio Garcia, um dos principais formuladores da política externa dos governos do PT, tem razão quando afirma: "é bom eliminar assim a ideia falsa de que a política externa não divide. Ela pode dividir, sim, e é bom que assim o seja, como ocorre nas democracias" (GARCIA, 20I4, p. 98).

Após o controverso impeachment de Dilma, Michel Temer assumiu e promoveu uma inflexão na política externa brasileira. A falta de legitimidade interna do seu governo aprofundou a crise existente desde 20I6, refletindo-se na débil inserção internacional do país. Em linhas gerais, a política externa brasileira realinhou o Brasil com as potências tradicionais (Estados Unidos, Europa e Japão), priorizando a diplomacia comercial, e abandonou a ênfase nas relações Sul-Sul, consideradas ideológicas. Temer manteve a participação do Brasil no Brics, mas enfatizou as relações bilaterais, sobretudo com a China, em detrimento da dimensão geopolítica do bloco.

A eleição presidencial de 2018 foi bastante polarizada e marcada pelo uso intensivo e estratégico das redes sociais. ${ }^{2}$ Ao fim de um processo eleitoral eivado de manipulações, Bolsonaro recebeu 57,8 milhões de votos, e Haddad, 47,0 milhões. Pela primeira vez na história do Brasil, um candidato de extrema-direita chegava à Presidência. Para alguns analistas, o pleito significou o fim da estrutura política que prevalecia desde o advento da Nova República, ameaçando também desconstituir o pacto social-democrata inscrito na Constituição Federal de 1988. Por um lado, a candidatura

Para Almeida (2019), o uso das redes sociais na campanha de Bolsonaro destoava das demais pela intensidade, pelas inversões de sentido e pela divulgação de falsas notícias, por exemplo, a suposta distribuição do chamado "kit gay" em escolas públicas por Fernando Haddad quando esteve à frente do Ministério da Educação no governo Dilma. 


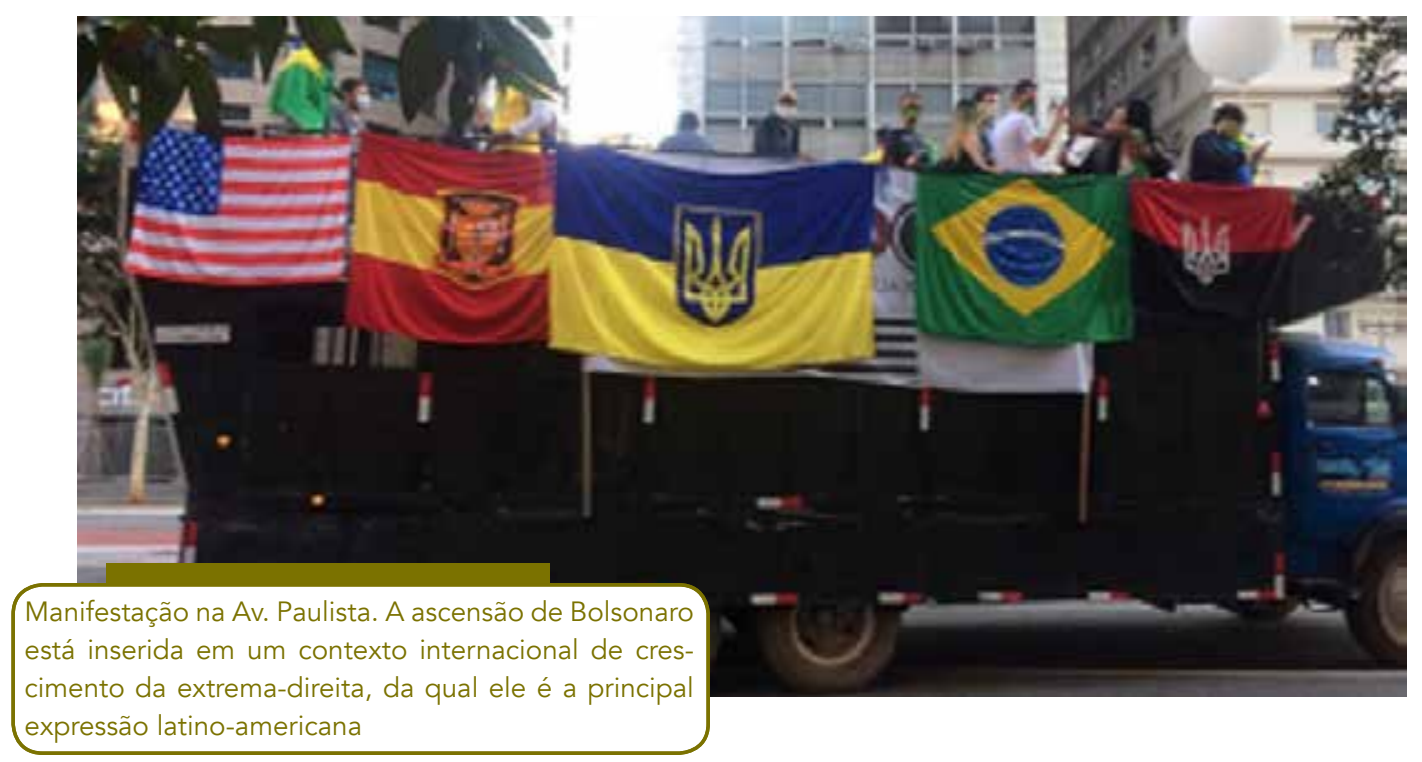

de Bolsonaro articulou uma agenda economicamente liberal, moralmente reguladora e socialmente intolerante. Por outro, a campanha de Haddad foi baseada na defesa da democracia, dos direitos humanos e da igualdade social (ALMEIDA, 20I9; CHAGAS-BASTOS, 2019).

A ascensão de Bolsonaro está inserida em um contexto internacional de crescimento da extrema-direita, da qual ele é a principal expressão latino-americana. A conjunção entre competição geopolítica, fim do boom de commodities e conflito distributivo interno levou ao esfacelamento da coalizão produtivista e à reunificação das classes empresariais em torno de uma agenda neoliberal. A luta contra a corrupção e contra o PT contribuiu para unificar a direita brasileira, que estava em ascensão desde 2013. Nesse sentido, a eleição de Bolsonaro foi uma espécie de "saída de emergência" das elites políticas e econômicas ao fracasso do governo Temer e à implosão das forças de centro-direita, sobretudo do PSDB, e contribuiu para a recuperação do protagonismo político das Forças Armadas (COGGIOLA, 20I9; LACERDA, 2019).

$\mathrm{O}$ atual presidente lidera uma coalizão neoconservadora que se estrutura em torno de ideias como o anticomunismo, a defesa da família patriarcal, o punitivismo securitário, o militarismo, o neoliberalismo econômico e o alinhamento externo aos Estados Unidos e a Israel. Trata-se de um movimento que reúne parcela da direita brasileira, sobretudo a direita cristã, e que tem inspiração no neoconservadorismo que levou Ronald Reagan ao poder nos anos I980. Segundo Lacerda (2019, p. 204), a doutrina neoconservadora foi resgatada no Brasil 40 anos depois porque, assim como no contexto estadunidense da época, no Brasil atual se articulam a reação contra o Estado de bem-estar social e a reação antifeminista, que são duas faces do neoconservadorismo.

Em linhas gerais, o governo Bolsonaro está dividido em três grupos. O primeiro é formado pelos seguidores de Olavo de Carvalho e ocupa sobretudo os ministérios 
da Educação e das Relações Exteriores. O segundo é composto pelas Forças Armadas, cujos integrantes ocupam a Vice-Presidência e ministérios importantes, como o da Defesa e a Casa Civil e o da Defesa, além de inúmeros cargos em toda a Esplanada. O terceiro grupo é formado por tecnocratas e ocupa especialmente a área econômica (CHAGAS-BASTOS, 20I9).

Em relação à presença dos militares no governo, o cientista político José $\mathrm{Mu}$ rilo Carvalho (CARVALHO, 20I9) observa que o presidente Bolsonaro cercou-se de dezenas de auxiliares oriundos das Forças Armadas, especialmente do Exército, em um número superior ao verificado nos governos militares (1964-I985). Segundo Carvalho, cinco das sete Constituições feitas após a independência do Brasil atribuem algum papel político às Forças Armadas. No caso da Constituição de I988, seu artigo I42 estabelece que as Forças Armadas "destinam-se à defesa da pátria, à garantia dos poderes constitucionais e, por iniciativa de qualquer destes, da lei e da ordem". Desde o advento da República, os militares têm exercido um papel de tutela das instituições democráticas. Após mais de 30 anos da volta da democracia, os militares retornaram ao poder após as eleições de 2018 , demonstrando a fragilidade do nosso regime democrático.

A política externa de Bolsonaro é baseada em uma visão missionária e cruzadista. O atual governo promove a aproximação entre política externa e religião, alegando que as pessoas que votaram em Bolsonaro esperavam que o Brasil defendesse no cenário internacional valores conservadores e cristãos. Com a escolha de Ernesto Araújo para chefiar o Itamaraty, dissipou-se qualquer dúvida acerca da direção da política externa do governo Bolsonaro. Além de ser um diplomata sem qualquer experiência como embaixador em postos importantes, Araújo é defensor de um típico pensamento neoconservador. $\mathrm{O}$ atual chanceler admira Trump por sua defesa dos valores ocidentais e enxerga "marxismo cultural" em questões como ambientalismo, feminismo e movimentos sociais, associados à vaga noção de globalismo (AMORIM, 20I9; BELÉM LOPES, 2020; LACERDA, 20I9; PINHEIRO; LIMA, 20I8b).

Apesar do alinhamento com os Estados Unidos e da subordinação ao governo Trump, deve-se observar que há certa distância entre a retórica agressiva de Bolsonaro e seus principais assessores e os interesses permanentes que movem a riqueza e alimentam o poder de determinados grupos, como o agronegócio. Nesse sentido, por mais que o atual mandatário brasileiro sinalize a favor de um alinhamento automático com a potência hemisférica, o comércio com a China tem crescido de maneira vertiginosa, enquanto o praticado com os Estados Unidos declina.

O governo Bolsonaro adotou um alinhamento automático e de grau inédito com os Estados Unidos, contribuindo para isolar o Brasil na cena global. Da mesma forma que os neoconservadores estadunidenses, os integrantes da atual coalizão têm Israel como "amigo" externo preferencial. Em relação ao "inimigo" externo, os neoconservadores brasileiros se opõem a uma versão contemporânea e localizada do comunismo, o bolivarianismo ou "socialismo do século XXI" na América do Sul (LA- 
CERDA, 20I9; PINHEIRO; LIMA, 20I8b). Como consequência de uma visão hostil e preconceituosa em relação aos vizinhos, é precisamente no plano regional que a atual política externa vem promovendo os retrocessos mais graves.

\section{O BRASIL E A AMÉRICA DO SUL: DA INTEGRAÇ̃̃O AUTÔNOMA À SUBORDINAÇ̃̃O HEMISFÉRICA}

Nos últimos 40 anos, a política externa brasileira pautou-se pela aproximação com os países vizinhos e foi indutora de projetos de integração regional. A Constituição de 1988 estabelece que o Brasil deverá buscar a integração latino-americana em suas diferentes dimensões (cultural, econômica, política e social). No início dos anos 1990, com a reorientação da política externa mexicana e a criação do Tratado de Livre-Comércio da América do Norte (Nafta), o conceito de América do Sul passou a se sobrepor ao de América Latina. Apesar das diferentes concepções e visões sobre a integração regional, os governos do PSDB e do PT mantiveram relações amistosas com todos os países da região, independentemente da orientação ideológica de seus governos. $\mathrm{O}$ atual governo brasileiro se afastou dos países vizinhos, rompendo com décadas de uma diplomacia que era respeitada em toda a região.

O governo Fernando Henrique concebeu a integração nos marcos do regionalismo aberto, como plataforma para o fortalecimento da inserção competitiva do Brasil na economia mundial. O programa do PSDB, que defendia o Mercosul nos anos I990, passou a defender a flexibilização do bloco a partir das eleições de 2002. Apesar de enfatizar a dimensão comercial do Mercosul, o governo Fernando Henrique promoveu a aproximação do bloco com a Comunidade Andina de Nações (CAN) e liderou a primeira reunião de presidentes sul-americanos, em 2000, ocasião em que foi lançada a Iniciativa para a Integração da Infraestrutura Regional Sul-Americana (Iirsa). Todavia, a ênfase do governo tucano sempre foi na dimensão econômica do processo integrativo.

A política externa de Lula tinha consciência do papel que uma América do Sul unida podia desempenhar em um mundo multipolar. A inserção soberana do país passava pela unidade da América do Sul, concebida como um importante ator geopolítico em uma ordem internacional em transformação. Nesse sentido, Lula revolucionou a maneira como o Brasil lidava com a região em três dimensões-chave: uma concepção de integração que incluía aspectos políticos e sociais e não apenas econômicos; o reconhecimento de assimetrias estruturais e a necessidade de enfrentá-las; e a consciência da forte relação entre a prosperidade do Brasil e a de seus vizinhos (PINHEIRO; LIMA, 20I8a).

Durante o governo Lula, o Mercosul foi considerado estratégico para o Brasil, que impulsionou a sua expansão, a qual resultaria na entrada da Venezuela em 20I2, e a ampliação da sua institucionalidade, com a criação do Fundo para a Convergência Estrutural do Mercosul (Focem) e do Parlamento do Mercosul (Parlasul), além de outras instituições vinculadas aos direitos humanos e à participação popular. $\mathrm{O}$ Focem 
tornou-se o principal instrumento para dirimir as assimetrias intrabloco e compensar as economias menores e as áreas menos desenvolvidas. Além disso, a importância do Mercosul deve-se ao fato de o bloco ser, historicamente, responsável pela absorção de grande parte do investimento externo direto do país e de aproximadamente $90 \%$ das exportações brasileiras de manufaturados.

A liderança de Lula foi decisiva para a criação da Unasul em 2008. Essa iniciativa teve um perfil diferente das outras, aproximando-se mais de um instrumento de governança regional do que dos padrões clássicos de integração. $\mathrm{O}$ arranjo percorreu o caminho inverso ao de outros blocos, que só adquiriram uma dimensão política após consolidarem a comercial. Por nunca ter sido um regime comercial, não competiu com nenhum dos regimes existentes nem pretendeu substituí-los, permitindo que os países pudessem cooperar em diversos campos de políticas públicas, como defesa, educação, saúde e infraestrutura. A Unasul atuou como um mecanismo de concertação, de construção de consensos, acomodando distintas visões sobre a integração. Ademais, a organização visava neutralizar qualquer intervenção estadunidense em assuntos políticos do subcontinente. Durante sua existência, os países sul-americanos puderam resolver episódios de instabilidade política na própria região, sem recorrer a Washington. Como afirmou Amorim (2016), com a Unasul a América do Sul deixou de ser um conceito meramente cartográfico e adquiriu um significado político.

No entanto, pressupor que a Unasul surgiu como "clube de amigos" dos governos progressistas significa desconhecer a história. A iniciativa da Unasul está em consonância com a visão geopolítica brasileira, que sempre foi mais sul-americana do que latino-americana, concebendo o fortalecimento da região como passo necessário para a projeção do Brasil como ator global. Essa visão é muito anterior à ascensão do PT e dos governos progressistas (CAETANO; LÓPEZ BURIAN; LUJÁN, 20I9).

No governo Dilma, houve uma retração da diplomacia brasileira na América do Sul. Dilma não conferiu à integração sul-americana a mesma importância dada por Lula. Apesar do engajamento nas missões da Unasul relativas à crise venezuelana, o Brasil ocupou uma posição marginal nos acordos de paz entre as Forças Armadas Revolucionárias da Colômbia (Farc) e o governo de Juan Manuel Santos. A fraca institucionalização de iniciativas prévias exacerbava o risco de retrocessos, como acabaria ocorrendo com a Unasul nos governos subsequentes. De fato, a política externa brasileira abandonou a vontade política demonstrada por Lula de articular visões favoráveis à construção de uma liderança regional. Assim, Celso Amorim tem razão quando observa que a política externa de Dilma continuou sendo "altiva”, mas muito menos "ativa” (PINHEIRO; LIMA, 20I8a; SARAIVA; VELASCO JÚNIOR, 20I6).

Foi no plano regional que o governo Temer mais se afastou da trajetória da política externa brasileira para a região. A pretensa "desideologização" das relações internacionais do Brasil implicou, na América do Sul, o abandono do exercício da liderança do país no subcontinente e o início da desconstrução da Unasul. Em 20I8, 
Brasil, Argentina, Colômbia, Chile, Peru e Paraguai comunicaram a suspensão de suas participações na Unasul. O anseio do governo Temer por rejeitar o legado dos governos petistas não foi acompanhado, entretanto, pela construção de uma nova estratégia de inserção do Brasil no seu entorno imediato, o que concorreu para agravar a instabilidade na região.

O governo Bolsonaro afastou o Brasil dos vizinhos e rompeu com a política externa brasileira não apenas para a América do Sul, mas para o conjunto da região. Nunca antes foi tão grande a distância entre as atitudes adotadas pelo governo e os interesses concretos do país. Do ponto de vista do interesse nacional, o Brasil deveria contribuir para que os países sul-americanos vivessem em paz e resolvessem seus conflitos por meio do diálogo. No entanto, ao violar os preceitos constitucionais da não intervenção e da solução pacífica de controvérsias, o Brasil está descartando um dos maiores trunfos de sua atuação diplomática: a vocação pacífica e o respeito pela soberania dos Estados nacionais (AMORIM, 20I9).

A crise venezuelana tem sido o pivô da paralisação progressiva e da implosão das principais organizações regionais de integração, sobretudo o Mercosul e a Unasul. O recente acordo entre o Mercosul e a União Europeia, que deve beneficiar sobretudo os monopólios europeus, deve levar a uma primarização ainda maior das economias regionais. Do ponto de vista político, representa uma rendição da diplomacia do Mercosul, especialmente do Itamaraty, cujos técnicos passaram décadas defendendo uma linha de negociação que agora se esfumaçou (CEPIK, 20I9; COGGIOLA, 2019).

Em 20I9, o Brasil denunciou oficialmente o tratado constitutivo da Unasul e declarou seu ingresso no Foro para o Progresso e Desenvolvimento da América do Sul (Prosul), arranjo regional dotado de exígua estrutura institucional que foi idealizado pelo Chile de Sebastián Piñera. Ao se retirar da Unasul, o Brasil saiu também de seus conselhos setoriais, como o Instituto Sul-Americano de Governo em Saúde (Isags), justo no momento em que o Brasil e a região se tornavam o epicentro da pandemia da covid-I9 (ALBUQUERQUE, 2020).

A coalizão conservadora tem adotado uma estratégia de inserção regional que representa uma ruptura com a trajetória da diplomacia brasileira das últimas décadas. Durante tal período, a política externa brasileira contribuiu para a estabilidade e a projeção regional. No atual contexto geopolítico, a subordinação do Brasil à potência hemisférica vem contribuindo para a instabilidade da região e para a transformação da América do Sul em palco de possíveis conflitos políticos.

\section{OS IMPACTOS DA COVID-19 NA ORDEM INTERNACIONAL E A RESPOSTA DA POLÍTICA EXTER- NA BRASILEIRA À PANDEMIA}

A atual pandemia está causando transformações na ordem internacional, com impactos geopolíticos e tendências socioeconômicas globais. A covid-I9 atingiu o Brasil e a América Latina em um momento delicado. O país e a região já estavam atravessando 
crises econômicas e instabilidade política. A ruptura na política externa torna-se ainda mais evidente diante da desastrosa reação do Brasil aos efeitos da atual pandemia.

De acordo com a OMS, a covid-I9 é a segunda pandemia do século XXI - a anterior foi a gripe A (HINI), entre 2009 e 20I0. Em 30 de janeiro de 2020, a organização declarou "emergência de saúde pública de importância internacional" (ESPII), buscando evitar que o novo coronavírus se tornasse uma pandemia. No entanto, a extensão geográfica da doença acabou levando a OMS a reconhecê-la como pandemia no dia II de março (ALBUQUERQUE, 2020; AITH et al., 2020).

A pandemia coincidiu com a crescente rivalidade entre a China e os Estados Unidos. Está em curso um claro processo de reposicionamento das duas potências no tabuleiro global. Se os anos 1990 marcaram o ápice do poder internacional estadunidense, atualmente assiste-se ao crescente papel da China nos planos econômico, geopolítico, institucional e normativo (MILANI, 2020).

Alguns analistas têm destacado algumas tendências agravadas pela pandemia. De um lado, a crise sanitária global tem fortalecido o nacionalismo autoritário em alguns países. O contexto da pandemia oferece a líderes autoritários a "desculpa perfeita" para romper com o Estado de direito e violar os direitos humanos, incluindo tanto os direitos individuais quanto os direitos econômicos, sociais e culturais. Nesse sentido, são ilustrativos os casos do Brasil, dos Estados Unidos e da Hungria. Por outro lado, a pandemia tem agravado as desigualdades socioeconômicas e atingido populações vulneráveis, com consequências desproporcionais entre classes, gêneros, gerações e grupos étnicos. Nos países do Sul, especialmente na América Latina, a pandemia tende a aumentar as desigualdades e a pobreza, acelerando a reversão dos avanços que haviam sido obtidos no início do século XXI (MILANI, 2020; THERBORN, 2020).

Em recente documento, a Comissão Econômica para a América Latina e o Caribe (Cepal) estima que a economia mundial deverá experimentar a maior contração desde a Segunda Guerra Mundial, e o PIB per capita deverá diminuir em 90\% dos países no mundo, em um processo sincrônico sem precedentes que atingirá fortemente os países da América Latina. Segundo a Cepal (2020, p. 9), o PIB da região deverá cair em média 9,I\% em 2020. Nesse cenário, o Brasil deverá ser um dos países latino-americanos mais afetados, com uma queda estimada de 9,2\% do seu PIB. Ademais, estima-se que o número de pessoas em situação de pobreza na região passará de I85,5 milhões, em 2019, para 230,9 milhões, em 2020. Já aquelas em situação de pobreza extrema passarão de 67,7 milhões, em 20I9, para 96,2 milhões neste ano, o que representa $15,5 \%$ da população latino-americana. Uma vez mais, o Brasil deverá ser um dos países mais atingidos no âmbito regional, com um crescimento de aproximadamente I2\% de pessoas pobres e miseráveis (CEPAL, 2020).

Em junho de 2020, a América do Sul converteu-se no novo epicentro do coronavírus, com destaque para o Brasil, que se tornou o segundo país no mundo com a maior quantidade de casos confirmados e de óbitos, atrás apenas dos Estados Unidos (SANTOS; ALBUQUERQUE, 2020). Como observou Rodrik (2020), a crise se desen- 
rolou de maneira previsível, a julgar pela natureza dos governos envolvidos. Nesse sentido, a postura anticientífica, o negacionismo e a irresponsabilidade do presidente estadunidense, Donald Trump, e do presidente brasileiro, Jair Bolsonaro, não deveriam causar surpresas.

Nos últimos anos, o Brasil tem sido visto com desconfiança pela comunidade internacional e até mesmo como ameaça pelos países vizinhos. Isolado e ausente das principais discussões multilaterais sobre a pandemia, tanto no âmbito global quanto no regional, o país vem se tornando cada vez mais refém de uma instabilidade política que flerta constantemente com a possibilidade de ruptura do regime democrático (SANTOS; ALBUQUERQUE, 2020). Para entender essa situação de isolamento do Brasil, faz-se necessário analisar a ruptura que o governo Bolsonaro vem realizando na política externa brasileira.

Desde o início da pandemia, a resposta do governo Bolsonaro foi desastrosa nos planos doméstico e internacional. No âmbito interno, a atuação do governo federal tem sido marcada pela falta de coordenação política, levando a conflitos e disputas de poder entre a União e as unidades federativas, de um lado, e o Poder Executivo e os demais poderes (Legislativo e Judiciário), de outro. Os governos subnacionais seguiram as recomendações da OMS e de especialistas em saúde e adotaram medidas de isolamento horizontal com o objetivo de retardar o avanço da epidemia. O governo Bolsonaro procurou contrariar essas decisões assinando diversos decretos federais definindo as atividades essenciais que deveriam ser mantidas durante a pandemia. Diante do conflito federativo, o STF decidiu intervir e autorizou que governadores e prefeitos implementassem medidas restritivas no combate à covid-I9 dentro da jurisdição de seus territórios, reservando à União a adoção de medidas em casos de abrangência nacional (SANTOS; ALBUQUERQUE, 2020).

O presidente minimizou a crise sanitária global e alinhou-se à ala ideológica do governo, apoiando-se em aliados no parlamento, segmentos empresariais e sua tradicional base social de extrema-direita. Esse comportamento entrou em conflito com a posição da maioria dos governadores e prefeitos, que procuraram seguir as principais recomendações da OMS e da comunidade científica nacional e internacional. Ademais, Bolsonaro sempre realçou os prejuízos econômicos que a política de isolamento horizontal da população (direcionada a todas as faixas etárias), recomendada pela maioria dos especialistas e adotada pelos governos subnacionais, poderia causar.

Da mesma forma que vem ocorrendo no plano doméstico, a política externa brasileira tem sido marcada pela falta de coordenação política e pelo crescente isolamento do Brasil diante dos principais interlocutores internacionais e regionais. $\mathrm{O}$ governo Bolsonaro seguiu Trump e responsabilizou a OMS pela demora na resposta à pandemia. Em junho de 2020, seguindo a decisão de Trump de romper com a OMS, por considerar que a organização favorece a China, o governo brasileiro ameaçou retirar o país do organismo multilateral. Pouco antes, o chanceler Ernesto Araújo havia publicado um texto em seu blog pessoal questionando o papel da OMS e argumen- 
tando que a covid-I9 representava um pretexto para o avanço global do comunismo (ARAÚJO, 2020). No entanto, a postura do chanceler foi duramente criticada por diferentes setores da sociedade brasileira, incluindo governadores e parlamentares, que sabem da importância estratégica da China para a economia brasileira (ALBUQUERQUE, 2020; SANTOS; ALBUQUERQUE, 2020).

$\mathrm{Na}$ América do Sul, o atual governo tem revertido todo um processo de colaboração sistemática institucionalizada que remonta às décadas de 1990 e 2000, por meio de organizações como o Mercosul e a Unasul. Embora o governo negue a importância estratégica do Mercosul, o Focem liberou recursos para um fundo emergencial de combate à covid-I9 nos países-membros (ALBUQUERQUE, 2020). Além disso, a implosão da Unasul encerrou os trabalhos do Conselho de Saúde Sul-Americano (CSS) e do Isags, principais iniciativas de coordenação em saúde na região.

Em síntese, a pandemia vem causando impactos geopolíticos e reforçando tendências políticas e sociais que fragilizam a democracia e aumentam as desigualdades sociais. A resposta do governo Bolsonaro à covid-ı tem sido até o momento desastrosa. O governo adotou uma postura anticientífica e negacionista. No plano doméstico, a resposta foi marcada pela falta de coordenação com os entes federativos e pelo conflito entre os poderes. No plano internacional, o alinhamento com os Estados Unidos isolou ainda mais o país. No início de outubro de 2020, o Brasil estava prestes a alcançar a marca de 150 mil mortos, fazendo crescer o uso da palavra genocídio para definir o comportamento do governo federal em relação à pandemia da covid-I9. Nesse sentido, o Tribunal Penal Internacional (TPI) já recebeu petições que apontam para a prática de genocídio e outros crimes contra a humanidade que teriam sido perpetrados pelo atual governo brasileiro.

\section{CONCLUSÃO}

A compreensão da política externa envolve dois níveis de análise: o estrutural ou sistêmico e o doméstico. No plano sistêmico, os conflitos geopolíticos e as crises do capitalismo afetam a inserção dos países, especialmente os periféricos, no sistema internacional, marcado por assimetrias e relações de poder. No nível doméstico, a orientação da política externa é influenciada pela visão de mundo da coalizão política doméstica. A política externa é uma política pública sui generis, integrada por elementos permanentes e contingentes. Apesar de lidar com temas sensíveis (defesa, segurança) que perpassam os diferentes governos, a política externa e a inserção internacional de determinado país também refletem o prolongamento, no plano internacional, do arranjo interno de poder e os interesses da coalizão política hegemônica.

Durante 30 anos após a Segunda Guerra Mundial, o arranjo entre Estado e mercado significou o primado da política sobre a economia, superando a propensão a crises inerentes ao capitalismo desregulado, desorganizado e caótico. Desde os anos I970, o fim do sistema de Bretton Woods e do consenso keynesiano levou ao advento 
do neoliberalismo. Apesar de a crise de 2008 ter abalado seus alicerces, a agenda de austeridade e a hegemonia do sistema financeiro não sofreram abalos. Nesse sentido, Streeck (20I8, p. 24) tem razão quando observa que na tensão entre capitalismo e democracia, a defesa neoliberal da justiça pura de mercado, se conduzida com habilidade, goza de enorme prestígio perante a opinião pública na luta contra a politização, a justiça social corretora do mercado.

A crise econômica mundial foi seguida pelo fim do boom de commodities e pelo aumento da competição entre os Estados Unidos e a China. Nos últimos anos, a estratégia de Washington tem sido enfrentar a crescente presença chinesa e desestabilizar os governos progressistas na América Latina. A guerra híbrida judicial-midiática levou à deposição de governos - o mais recente foi o de Evo Morales, na Bolívia - e à prisão e perseguição de lideranças, como nos casos de Lula e Rafael Correa, respectivamente, o que contribuiu para a ascensão da extrema-direita na região.

Como observam Pinheiro e Lima (20I8a), a política externa implica agência e a possibilidade de fazer diferentes escolhas, mesmo em uma situação de dependência estrutural. Apesar de a agência sozinha não ter capacidade de alterar as condições estruturais, ela pode contribuir para modificar os termos de inserção de um país na ordem internacional. No caso do Brasil, longe de ser uma constante na trajetória da sua política externa, as estratégias autonomistas representaram momentos de ruptura e descontinuidade, envolvendo a combinação de oportunidades sistêmicas e a agência de atores centrais no plano doméstico3.

Os governos do PT adotaram uma política externa autônoma que enfatizou as relações Sul-Sul e a integração regional. O surgimento de coalizões como o Brics e o Ibas e a criação de blocos como a Unasul projetaram o Brasil e a América do Sul no sistema internacional, contribuindo para a formação de um mundo multipolar. No entanto, essa política exterior gerou reações da potência hegemônica e das elites brasileiras, cujo compromisso democrático sempre foi débil ao longo da história.

As eleições de 2018 estão inseridas no contexto de uma onda conservadora mundial. A vitória de Bolsonaro, portanto, deve-se à conjunção de fatores externos e internos. De um lado, integra a atual estratégia de Washington para a região, em um quadro de acirramento da rivalidade sino-americana. De outro, reflete o funcionamento disfuncional das instituições brasileiras. Com efeito, a última eleição possibilitou o retorno dos militares ao poder, fragilizando ainda mais a débil democracia brasileira.

A polarização política no plano doméstico teve reflexos diretos na política externa brasileira. O alinhamento com a potência hegemônica e a subordinação à administração Trump revelam um grau de servilismo e fervor ideológico inéditos na história da política externa do país. Apesar de suas diferenças, os governos Fernando Henrique, Lula e Dilma combinaram doses adequadas de crenças e princípios nor-

3 Pinheiro e Lima (2018a, p. 19) identificam quatro períodos de ruptura, em que prevaleceu uma lógica autonomista na política externa brasileira: a política dual de Getúlio Vargas, a política externa independente de Jânio Quadros-João Goulart, o pragmatismo responsável de Ernesto Geisel e a política externa "altiva e ativa" de Lula e Celso Amorim. 


\section{A crise sanitária global vem causando impactos à ordem geopolítica ao intensificar as agressões dos Estados Unidos à China, ao erodir a democracia em diferentes países e aumentar as desigualdades sociais e a pobreza em todo o mundo, sobretudo na América Latina}

mativos sobre o que consideravam o melhor para o país com certo pragmatismo em virtude da natureza da inserção brasileira no mundo (PINHEIRO; LIMA, 20I8b).

A atual política externa contribui para destruir uma política que, durante décadas, havia tornado o Brasil um ator respeitado na América Latina e fonte de estabilidade na região. Até o momento, a diplomacia brasileira já provocou o rebaixamento do Mercosul e a implosão da Unasul. Nesse sentido, a atual política externa sabota qualquer projeto de integração autônoma, desestabiliza a região e isola o Brasil no sistema internacional.

A crise sanitária global vem causando impactos à ordem geopolítica ao intensificar as agressões dos Estados Unidos à China, ao erodir a democracia em diferentes países e aumentar as desigualdades sociais e a pobreza em todo o mundo, sobretudo na América Latina. A resposta do governo Bolsonaro à pandemia tem sido desastrosa. A atual política externa tem sido responsável pela desconstrução da histórica atuação do Brasil na área de saúde. O país sempre foi reconhecido como um importante ator em defesa da saúde como direito humano fundamental, tanto no plano multilateral quanto no âmbito regional. Aliás, o retrocesso vai além da saúde e envolve áreas como cultura, gênero, LGBTs, meio ambiente e povos indígenas, entre outras. Nunca foi tão atual aquilo que Celso Furtado afirmou em uma de suas últimas obras: "Em nenhum momento de nossa história foi tão grande a distância entre o que somos e o que esperávamos ser" (FURTADO, I999, p. 26).

* Doutor em Ciência Política pelo Instituto de Estudos Sociais e Políticos da Universidade do Estado do Rio de Janeiro (lesp-Uerj) e assessor de Relações Internacionais do Instituto Nacional de Infectologia Evandro Chagas (INI), da Fiocruz. Mestre em Relações Internacionais pela PUC-Rio e pesquisador do Laboratório de Análise Política Mundial (Labmundo) do lesp-Uerj. E-mail: tiagonnery@gmail.com

Texto recebido em setembro de 2020; aprovado em outubro de 2020. 
AITH, Fernando M. A. et al. Direitos na pandemia: Boletim n. 1 - mapeamento e análise das normas jurídicas de resposta à covid-19 no Brasil. São Paulo: Cepedisa-USP/Conectas Direitos Humanos, 2020. Disponível em: <http://cepedisa.org.br/publicacoes>. Acesso em: 11 ago. 2020.

ALBUQUERQUE, Marianna. Globalização da saúde pública: a Organização Mundial da Saúde e a cooperação na América do Sul. Boletim Opsa, Rio de Janeiro, n. 2, p. 7-16, abr.-jun. 2020.

ALLISON, Graham. Destined for war: can America and China escape Thucydides's trap?. Nova York: Mariner Books, 2018.

ALMEIDA, Ronaldo de. Bolsonaro presidente: conservadorismo, evangelismo e a crise brasileira. Novos Estudos Cebrap, São Paulo, v. 38, n. 1, p. 185-213, jan.-abr. 2019.

AMORIM, Celso. A grande estratégia do Brasil: discursos, artigos e entrevistas da gestão no Ministério da Defesa (2011-2014). Brasília: Funag; São Paulo: Unesp, 2016.

Nau sem rumo: a política externa brasileira no início de 2019. Margem Esquerda, São Paulo, n. 32, p. 33-39, jan.-jun. 2019.

ARAÚJO, Ernesto. Chegou o comunavírus. Metapolítica 17. 22 abr. 2020. Disponível em: <https:// www.metapoliticabrasil.com/post/chegou-o-comunav\%C3\%ADrus>. Acesso em: 10 set. 2020.

BELÉM LOPES, Dawisson. De-westernization, democratization, disconnection: the emergence of Brazil's post-diplomatic foreign policy. Global Affairs, Norman, v. 6, p. 167-184, jun. 2020. Disponível em: https://www.tandfonline.com/doi/full/10.1080/23340460.2020.1769494. Acesso em: 10 set. 2020.

BOITO JR., Armando. Reforma e crise política no Brasil: os conflitos de classe nos governos do PT. Campinas: Editora Unesp, 2018.

BOYER, Robert. Teoria da regulação: os fundamentos. São Paulo: Estação Liberdade, 2009.

CAETANO, Gerardo; LOPEZ BURIAN, Camilo; LUJÁN, Carlos. El Brasil de Bolsonaro, las orientaciones posibles de su política exterior y el futuro del regionalismo en Sudamérica. Revista Uruguaya de Ciencia Política, v. 28, n. 1, p. 95-130, jun. 2019.

CARVALHO, José Murilo. Forças Armadas e política no Brasil. São Paulo: Todavia, 2019.

CEPAL. Enfrentar los efectos cada vez mayores del covid-19 para una reactivación con igualdad: nuevas proyecciones. Informe especial n. 5, jul. 2020. Disponível em: <www.cepal.org/es/ publicaciones/45782-enfrentar-efectos-cada-vez-mayores-covid-19-reactivacion-igualdad-nuevas $>$. Acesso em: 20 ago. 2020.

CEPIK, Marco. O corolário Trump e a América Latina. Revista Tempo do Mundo, Porto Alegre, v. 5, n. 1, p. 241-265, jan. 2019.

CHAGAS-BASTOS, Fabrício H. Political realignment in Brazil: Jair Bolsonaro and the right turn. Revista de Estudios Sociales, Bogotá, v. 69, p. 92-100, jul.-set. 2019. Disponível em: http://www.scielo.org. co/scielo.php?script=sci_arttext\&pid=S0123-885X2019000300092. Acesso em: 10 set. 2020.

COGGIOLA, Osvaldo. América Latina em convulsão histórica. Margem Esquerda, São Paulo, n. 33, 84-98, jul.-dez. 2019.

FURTADO, Celso. O longo amanhecer: reflexões sobre a formação do Brasil. Rio de Janeiro: Paz e Terra, 1999.

GARCIA, Marco Aurélio. Avanços, impasses e desafios da integração. In: MARINGONI, Gilberto; SCHUTTE, Giorgio Romano; BERRÓN, Gonzalo. (Org.). 2003-2013: uma nova política externa. Tubarão: Editora Copiart, 2014. p. 96-107.

JUDT, Tony. Pós-guerra: uma história da Europa desde 1945. Rio de Janeiro: Objetiva, 2008.

LACERDA, Marina Basso. O novo conservadorismo brasileiro: de Reagan a Bolsonaro. Porto Alegre: Zouk, 2019. 
MILANI, Carlos R. S. Covid-19 between global human security and ramping authoritarian nationalisms. Geopolítica(s), Madri, v. 11, n. especial, p. 141-151, maio 2020.

Solidariedade e interesse: motivações e estratégias na cooperação internacional para o desenvolvimento. Curitiba: Appris, 2018.

; PINHEIRO, Letícia. The politics of Brazilian foreign policy and its analytical challenges. Foreign Policy Analysis, Oxford, n. 13, p. 278-296, 2017.

PINHEIRO, Letícia; LIMA, Maria Regina Soares de. Between autonomy and dependency: the place of agency in Brazilian foreign Policy. Brazilian Political Science Review, São Paulo, v. 12, n. 3, out. 2018 . 2018b.

Uma diplomacia amadora com resultados desastrosos. Boletim Opsa, n. 3, p. 4-5, jul.-set.

RICUPERO, Rubens. A diplomacia na construção do Brasil: 1750-2016. Rio de Janeiro: Versal, 2017.

RODRIK, Dani. Will covid-19 remake the world?. Project Syndicate, Praga, 6 abr. 2020. Disponível em: <www.project-syndicate.org/commentary/will-covid19-remake-the-world-by-dani-rodrik-202004? barrier=accesspaylog>. Acesso em: 11 ago. 2020.

SANTOS, Leandro Wolpert dos; ALBUQUERQUE, Marianna. A pandemia de covid-19 nas políticas doméstica e externa do Brasil: disputa entre poderes institucionais, alinhamento aos EUA e isolamento internacional. Boletim Opsa, n. 2, abr.-jun., p. 19-39, 2020. Disponível em: http://opsa.com.br/wpcontent/uploads/2017/01/Boletim_OPSA_2020_n2_abr-jun-1.pdf. Acesso em: 10 set. 2020.

SANTOS, Wanderley Guilherme. A democracia impedida: o Brasil no século XXI. Rio de Janeiro: FGV Editora, 2017.

SARAIVA, Miriam Gomes; VELASCO JÚNIOR, Paulo Afonso. A política externa brasileira e o "fim de ciclo" na América do Sul: para onde vamos?, Pensamiento Propio, Buenos Aires, n. 21, p. 295-324, 2016.

SERRANO, Franklin. Relações de poder e a política macroeconômica americana, de Bretton Woods ao padrão dólar flexível. In: FIORI, José Luís. (Org.). O Poder americano. Rio de Janeiro: Vozes, 2004.

SINGER, André. O lulismo em crise: um quebra-cabeça do período Dilma (2011-2016). São Paulo: Companhia das Letras, 2018.

Os sentidos do lulismo: reforma gradual e pacto conservador. São Paulo: Companhia das Letras, 2012.

SPEKTOR, Matias. Diplomacia da ruptura. In: Democracia em risco?: 22 ensaios sobre o Brasil hoje. São Paulo: Companhia das Letras, 2019.

STREECK, Wolfgang. Tempo comprado: a crise adiada do capitalismo democrático. São Paulo: Boitempo, 2018.

STUENKEL, Oliver. 0 mundo pós-ocidental: potências emergentes e a nova ordem global. Rio de Janeiro: Zahar, 2018.

THERBORN, Göran. Dreams and nightmares of the world's middle classes. New Left Review, Londres, n. 124, p. 63-87, jul.-ago. 2020.

VAROUFAKIS, Yanis. 0 minotauro global: a verdadeira origem da crise financeira e o futuro da economia global. 2 ed. São Paulo: Autonomia Literária, 2016. 